\title{
Recycled Waste Glass Powder as Binder for Sustainable Concrete
}

Z. Kalakada 1

Email zameer.kalakada@griffithuni.edu.au

J. H. Doh $1 \square$

Email j.doh@griffith.edu.au

1 School of Engineering and Built Environment, Griffith University, Brisbane, QLD, 4222, Australia

\section{Abstract}

The main focus of this study is to investigate the pozzolanic attribute of the recycled waste glass powder used as cement replacement. A coarser glass powder $(<150 \mu \mathrm{m})$ was used and the substitution levels employed were 0,15 and $30 \%$ by weight of cement. A mix design similar to that of fly ash was used in the current experimental program in order to enhance the performance of the glass powder (GP) under investigation. In addition to principal tests like workability, density and compressive strength durability tests such as drying shrinkage and resistance to chloride ion penetration were performed. Temperature of the mixes was also evaluated to ascertain the effect of GP on heat of hydration. Test results show that $30 \%$ is the ideal replacement level which lead to higher strength reporting a strength activity index (SAI) of over $100 \%$, improved resistance to chloride permeability and lower density, drying shrinkage and temperature.

AQ1

\section{Keywords}

Waste glass

Cement replacement

Pozzolan

Strength activity index

Sustainability

\section{Introduction}


Waste Glass disposal is fast becoming an upheaval task globally, owing to low recycling rate, limited storage spaces and shortage in new spaces for landfills [2, 17]. Since glass is non-biodegradable, disposing it in the landfill is environmentally unsustainable. On the other hand, cement production is one of the main reasons for the global warming since leading to discharge of almost similar amount of carbon dioxide in the atmosphere. There has been numerous studies, reported in the literature which successfully employed pozzolanic materials like fly ash; blast furnace slag and silica fume as partial replacement of cement but as the methodology is value-added it is imperative to look out for other readily available waste materials which can exhibit cementitious properties $[1,12,13,14,21,25]$. Recently it's revealed that glass when grinded to a particular fineness exhibits pozzolanic characteristics.

In the early days, waste glass was used in concrete as an aggregate replacement and it was observed that the mechanical and durability properties of the modified concrete were degraded due to the increased potential of Alkali-Silica Reaction (ASR) (Etris et al. 1974), [20, 27]. The main reason for this deterioration was due to high percentage of silica in glass cullets which increased the chances of ASR in the concrete. Taha and Nounu [26] explained that ASR is a deleterious expansion occurring in concrete due to the reaction between siliceous minerals present in aggregate and the alkaline pore solution in concrete. Later, Investigations have shown that ASR occurrence in concrete is dependent on the particle size distribution of glass used, as the particle size decreases the ASR probability reduces $[22,23]$. The suppressive effect of glass powders on the ASR expansion in concrete was due to the pozzolanic characteristic of glass powder, similar to other pozzolanic materials such as fly ash, silica fume and metakaolin $[7,19]$. These results motivated the application of recycled waste glass powder with microscopic particle size distribution as cement replacement in concrete. AQ2

Experimental investigations have reported that glass when grinded to about $300 \mu \mathrm{m}$ showed negligible ASR but beyond $300 \mu \mathrm{m}$, silica in glass tend to react with the alkalis and would lead to cracks owing to ASR (Farshad et al. 2010), [3, $4,23]$. Mehta [15] stated that the pozzolanic reaction in glass particle initiates at approximately below $300 \mu \mathrm{m}$ and when the fineness is reduced to about $100 \mu \mathrm{m}$ the pozzolanicity of the glass exceeds that of fly ash at low cement replacement levels and after curing of 90 days. Shao et al. [22] is foremost in the research pertaining to GP as cement replacement and the size of the glass particle ranged from 38-150 $\mu \mathrm{m}$. Of late, the researchers concentrated on finer glass particle size ranging from $0-100 \mu \mathrm{m}$ and the maximum percentage of cement replacement is $60 \%[5,6,11,16]$. There is no agreement on the ideal 
replacement level of GP reported in the numerous studies done so far as the performance of GP is dependent on several factors including: particle size; chemical composition; and experimental parameters.

Most of the research done in the past relating to GP as binder replacement employed a finer GP $(<100 \mu \mathrm{m})$, this is one of the few studies in which a coarser GP is employed and the pozzolanic performance of the GP is improved by modifying the mix design.

\section{Experimental Program}

The cement used in this project is general purpose cement which complies with all the regulations and requirements highlighted in AS 3972 for general purpose and blended cement. GP $(95 \%<150 \mu \mathrm{m})$ used in the current study was obtained from a recycling centre based in Brisbane (Envirosand). Fine aggregate passing $4.75 \mathrm{~mm}$ sieve was used in the preparation of the mixtures having a specific gravity of 2.48, water absorption of $1.5 \%$ and fineness modulus of 2.5 . A weight based mix design was used to design a control target strength of $32 \mathrm{MPa}$ the details of which are shown in Table 1. GP tends to increase the workability due to its water reducing ability, additionally the specific gravity of GP (2.46) is similar to that of fly ash (2.5) hence applied an efficiency factor $(\mathrm{k}=0.3)$ akin to that of fly ash mix design [9]. Super plasticizer (SP) content was slightly reduced in GP mixes in order to maintain similar slump with the control mix as seen in Table 1. Concrete cylinders of dimension $100 \mathrm{~mm}$ (diameter) and $200 \mathrm{~mm}$ (height) were prepared in accordance with AS 1012.8.1, each mix had 15 cylinders for density, strength and chloride resistance measurements, additionally 3 prisms of $75 \times 75 \times 275 \mathrm{~mm}$ were cast for measuring the drying shrinkage as per AS 1012.13. Drying shrinkage testing was done for a period of 56 days and heat of hydration of the mixes was evaluated using an EL-USB-TCLCD thermocouple data logger for a period of seven days. Fresh concrete was poured in a vacuum flask, the lid of the flask was drilled to enable one end of the $\mathrm{K}$-type temperature probe in the mortar while the other end is connected to the thermocouple data logger to monitor the temperature of the mix every $5 \mathrm{~min}$.

\section{Table 1}

Mix design (corresponding to a volume of $0.03 \mathrm{~m}^{3}$ )

\begin{tabular}{|l|l|l|l|l|l|l|l|l|}
\hline $\begin{array}{l}\text { Mix } \\
\text { id }\end{array}$ & $\begin{array}{l}\text { GP } \\
\mathbf{( \% )}\end{array}$ & $\begin{array}{l}\text { Cement } \\
\mathbf{( k g )}\end{array}$ & $\begin{array}{l}\text { GP } \\
\mathbf{( k g )}\end{array}$ & $\begin{array}{l}\text { Sand } \\
\mathbf{( k g )}\end{array}$ & $\begin{array}{l}\text { Water } \\
\mathbf{( k g )}\end{array}$ & $\begin{array}{l}\text { W/(C) } \\
\mathbf{0 . 3 G P}\end{array}$ & $\begin{array}{l}\text { SP } \\
\mathbf{( k g )}\end{array}$ & $\begin{array}{l}\text { Slump } \\
\mathbf{( m m})\end{array}$ \\
\hline $\begin{array}{l}\text { M1- } \\
0 \%\end{array}$ & 0 & 17.9 & 0 & 42.1 & 7.5 & 0.42 & 0.27 & 250 \\
\hline $\begin{array}{l}\text { M2- } \\
15 \%\end{array}$ & 15 & 16.1 & 2.8 & 41.4 & 7.1 & 0.42 & 0.24 & 245 \\
\hline
\end{tabular}




\begin{tabular}{|l|l|l|l|l|l|l|l|l|}
\hline $\begin{array}{l}\text { Mix } \\
\text { id }\end{array}$ & $\begin{array}{l}\text { GP } \\
(\mathbf{\%})\end{array}$ & $\begin{array}{l}\text { Cement } \\
(\mathbf{k g})\end{array}$ & $\begin{array}{l}\text { GP } \\
\mathbf{( k g )}\end{array}$ & $\begin{array}{l}\text { Sand } \\
\mathbf{( k g )}\end{array}$ & $\begin{array}{l}\text { Water } \\
\mathbf{( k g )}\end{array}$ & $\begin{array}{l}\text { W/(C) } \\
\mathbf{0 . 3 G P})\end{array}$ & $\begin{array}{l}\text { SP } \\
\mathbf{( k g )}\end{array}$ & $\begin{array}{l}\text { Slump } \\
(\mathbf{m m})\end{array}$ \\
\hline $\begin{array}{l}\text { M3- } \\
30 \%\end{array}$ & 30 & 14.5 & 6.2 & 39.9 & 6.9 & 0.42 & 0.22 & 240 \\
\hline
\end{tabular}

The workability of the fresh concrete is determined by slump cone test in accordance with the standard AS 1012.3.1. AS 1012.12 was used to measure the hardened density of cylindrical samples at 7,28 and 91 days of curing. The compressive strength test of all the concrete cylinders was performed at 7, 28 and 91 days of curing in accordance with AS 1012.9. An average of five cylinders was taken for each testing age in order to keep the standard deviation to a bare minimum. Resistance to chloride ion penetration was evaluated by using Resipod which complies with the standard AASHTO TP 95. Resipod is a fully integrated 4-point Wenner probe used to measure the electrical resistivity of concrete cylinders non-destructively. Current is applied at the two outer probes and the resulting potential difference between the two inner probes is reported as the resistivity of the specimen, the applied current is passed by the ions in the pore liquid. For each cylinder, an average of eight readings is taken as the final resistivity value which is expressed in $\mathrm{k} \Omega \mathrm{cm}$. In majority of the cases, the resistivity results from the Resipod have shown a good correlation with chloride exposure tests, like ASTM C-1556, on cylinders cast from the same concrete mix [8].

\section{Results}

\subsection{Hardened Density}

Density of all the mixes increases linearly with an increase in curing age as seen in Fig. 1. There is a minor reduction in the densities with the increasing GP content, mix with $30 \%$ GP recorded the least densities at all curing ages. The possible reason may be due to the fact that the specific gravity of GP used is 2.45 compared to the cement which has a specific gravity of 3.15 .

Fig. 1

Hardened density of the mixes 


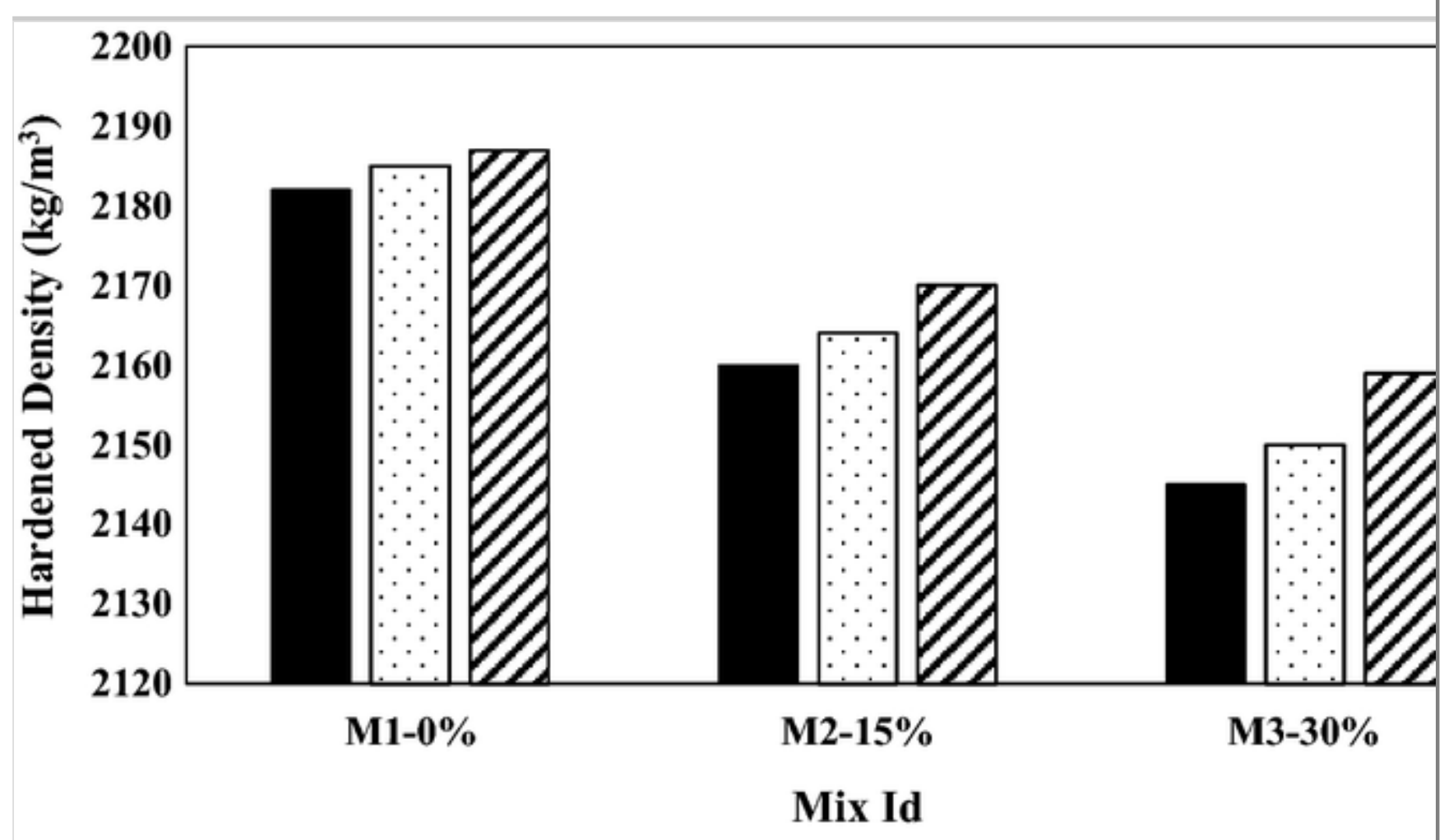

-7-Day $\square 28-D a y$ [91-Day

\subsection{Compressive Strength and Strength Activity Index}

Compressive strength results are illustrated in Fig. 2, control mix with 0\% GP showed highest strength values compared to GP mixes at 7 and 28 days of curing. However, at prolonged curing of 91 days, mix with 30\% GP showed better strength compared to the control mix. From 28 to 91 days, GP mixes with 15 and $30 \%$ reported a rise in strength by 18 and $10 \%$ respectively while the control mix had an increment of only 3\% illustrating the notable effect of GP. This improved performance, particularly at later stage is due to the secondary hydration brought about by the pozzolanic reaction in GP mixes.

Fig. 2

Compressive strength of mixes 


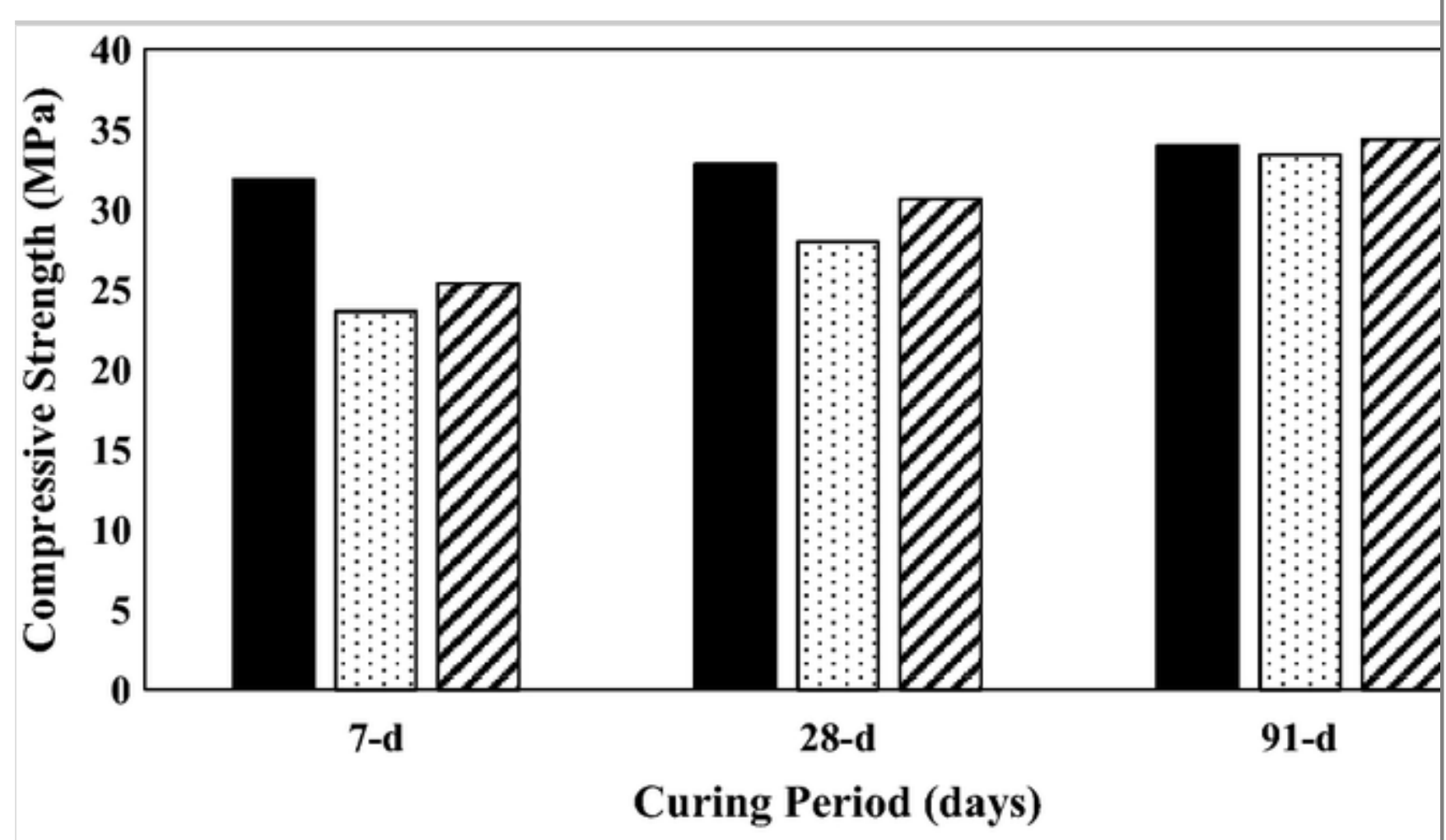

$\square \mathrm{M1-0} \% \quad \square \mathrm{M} 2-15 \% \quad \square \mathrm{M3}-30 \%$

The pozzolanic performance of GP may be estimated with the Strength Activity Index (SAI), which is the ratio between strength of mortar containing GP and strength of equivalent reference mortar at the same age. As seen in Fig. 3, mix with $30 \%$ GP showed the highest SAI at all testing age reporting SAI values of 80,93 and $101 \%$ at 7,28 and 91 days of curing period respectively.

Fig. 3

Strength activity index of the mixes 


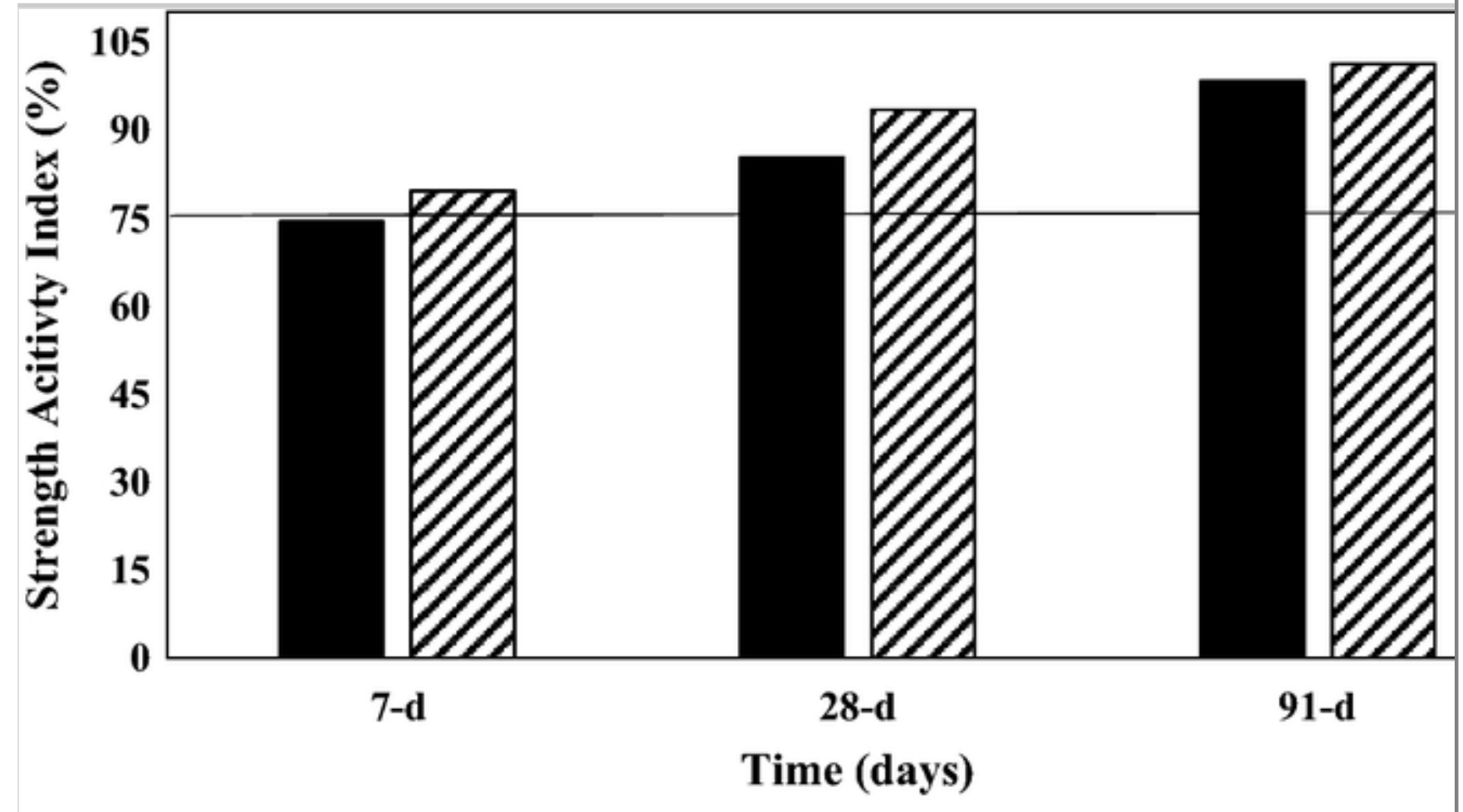

- M2-15\% \M3-30\%

\subsection{Resistance to Chloride Ion Penetration}

Chloride resistance of the mixes measured using Resipod are depicted in Fig. 4. As can be seen, higher the GP content, more would be the resistance value. Both 15 and 30\% GP mixes showed a higher resistance to chloride ion penetration compared to the control mix at all testing ages. The resistance value increased with the curing age in all mixes, mix with 0,15 and $30 \%$ GP showed a resistivity of 19,23 and $25 \mathrm{k} \Omega \mathrm{cm}$ respectively at 91 days of curing. GP illustrated a much improved resistance compared to the control mix especially at prolonged curing of 91-days and hence fell in the category of low risk of chloride permeability.

Fig. 4

Chloride resistance of the mixes 


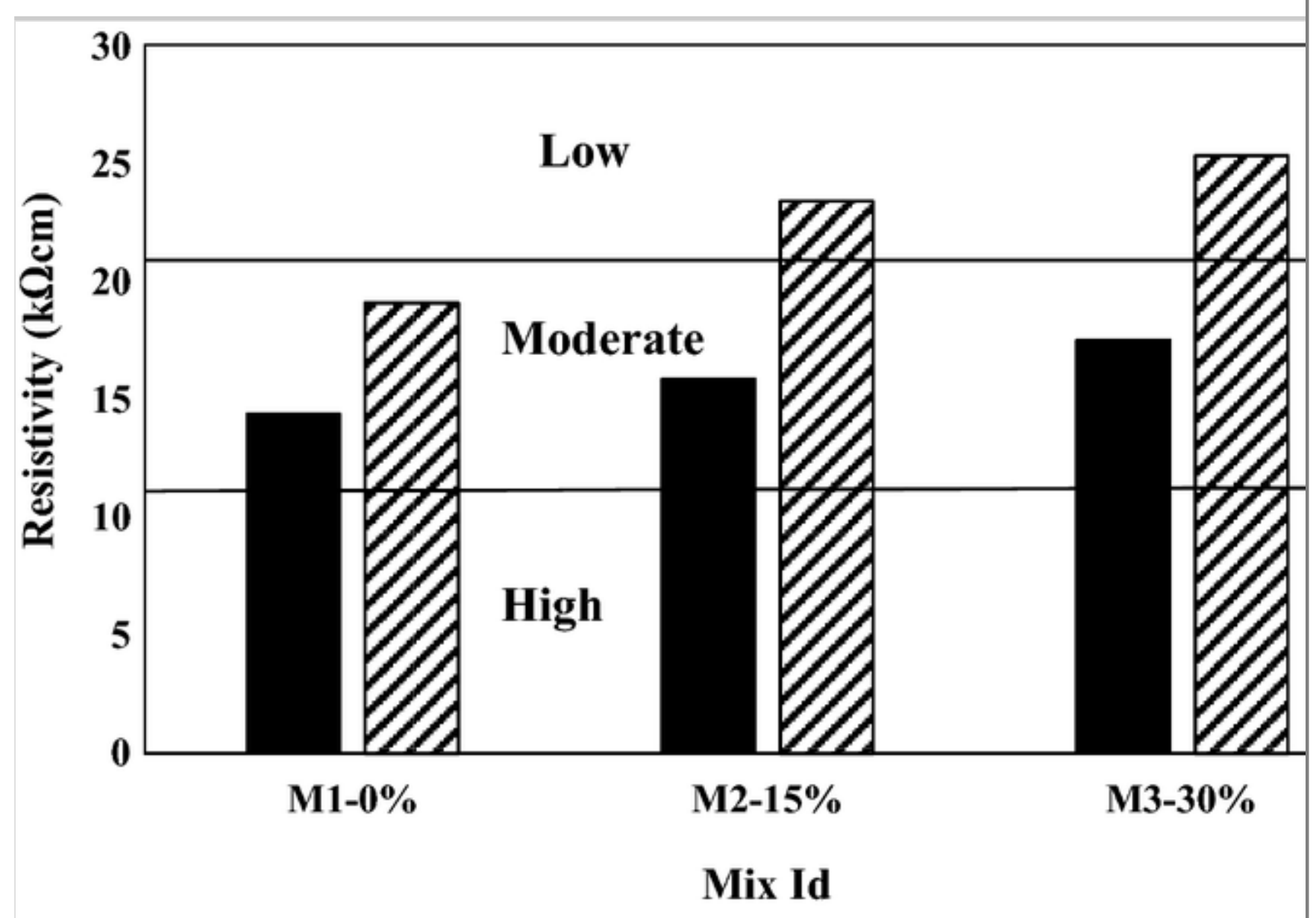

28-d Cl Res घ91-d Cl Res

\subsection{Drying Shrinkage}

Results of drying shrinkage of the mixes can be seen in Fig. 5. Both the GP mixes showed a slightly higher shrinkage value compared to the control mix until 28 days but subsequently ended up a bit on the lower side with respect to the control mix at final drying age of 56 days.

Fig. 5

Drying shrinkage of the mixes 


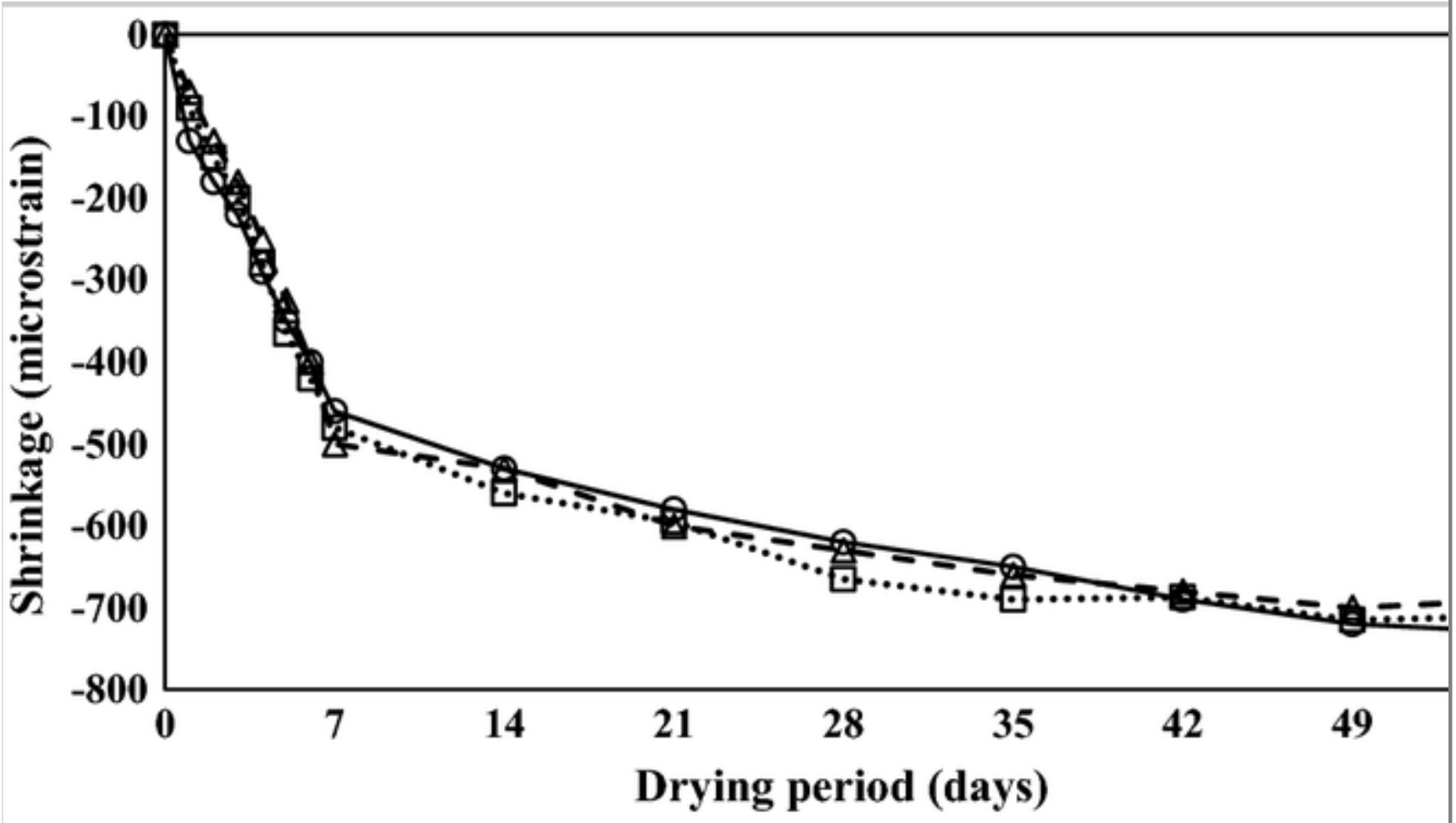

- M1-0\% …

At 56 days, the lowest shrinkage of 690 microstrain was recorded by the mix with $30 \%$ GP, while the control and 15\% GP reported 730 and 710 microstrain respectively. The slight improvement in the shrinkage of GP mixes compared to the plain mix is due to the lower water content owing to water reductions of 12.5 and $20 \mathrm{~kg} / \mathrm{m}^{3}$ applied to mixes with 15 and 30\% GP respectively in accordance with fly ash mix design [9]. Another study reported similar shrinkage results with a higher water to cementitious material ratio of 0.49 , however, GP mixes showed higher shrinkage values compared to the control mix this may be due to absence of water reductions in the mix design [24].

\subsection{Heat of Hydration}

The heat of hydration of the mixes was evaluated using EL-USB thermocouple data logger, the results of which are shown in Fig. 6. It can be seen that as the GP content increases the temperature reduces, mix with $30 \%$ GP recorded the lowest temperature of $41.5{ }^{\circ} \mathrm{C}$, while $15 \%$ GP resulted in $49{ }^{\circ} \mathrm{C}$, the highest temperature of $52{ }^{\circ} \mathrm{C}$ was reported by the control mix with $0 \%$ GP. The lower heat of hydration in GP mixes is most likely due to the combined effect of decrease in cement content and increased secondary hydration owing to pozzolanic characteristic of GP.

Fig. 6

Heat of hydration of the mixes 


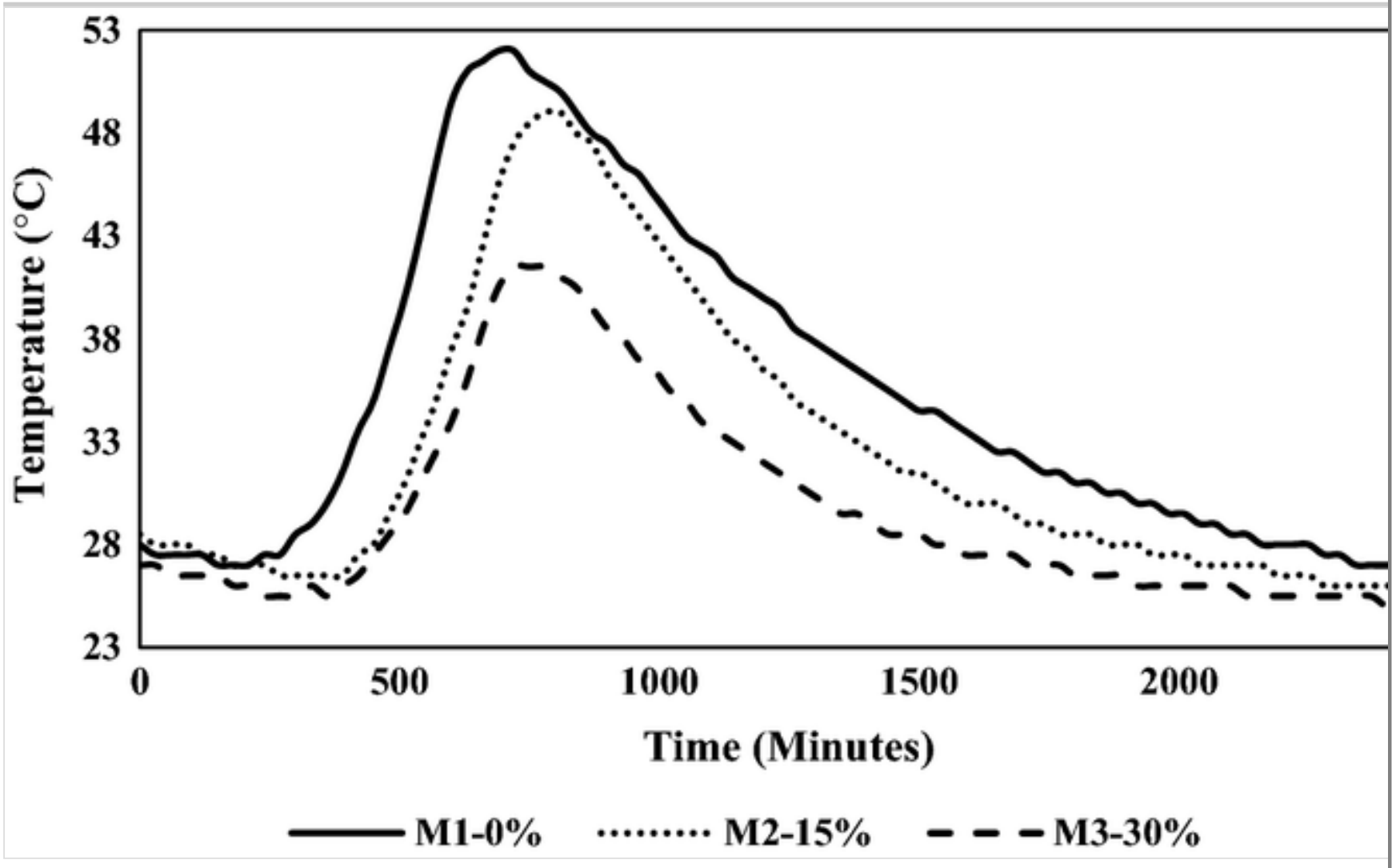

\section{Conclusions}

This study presents experimental results on the use of coarser GP as binder in concrete. Unlike previous work, this study altered the mix design in order to maximize the pozzolanic attribute of GP. Based on the newly obtained results, following conclusions can be drawn:

- Hardened density results indicate that GP replacement would lead to lighter concrete;

- For a control mix with $32 \mathrm{MPa}$ design strength, GP mixes with 15 and $30 \%$ replacement resulted in compressive strengths of 33 and $34 \mathrm{MPa}$ respectively at curing age of 91 days;

- Mix with 30\% GP showed SAI values of greater than $75 \%$ at all curing ages and hence the GP under examination can be used as a pozzolanic material in concrete;

- Resistance to chloride ion penetration increased with the GP substitution, with respect to the control mix, the increment in resistance is about 23 and $33 \%$ with 15 and $30 \%$ replacement respectively;

- GP mixes resulted in slightly lesser shrinkage resulting in reducing the drying shrinkage by 3 and $6 \%$ in comparison to control mix at 15 and 30\% 
substitution respectively;

- There is a significant depletion in the heat of hydration due to GP replacement, $30 \%$ GP resulted in $20 \%$ reduction;

As part of current experiment tests, $30 \%$ of GP replacement of concrete is the ideal replacement level which showed better strength, higher resistance to chloride ion penetration and lower density, shrinkage and temperature.

\section{Acknowledgements}

Special thanks to Mr. Paul Howard and Mr. Des Chalmers (Envirosand, Brisbane), for providing the GP for the research project at their own expense.

\section{References}

1. Arulrajah A, Disfani MM, Haghighi H, Mohammadinia A, Horpibulsuk S (2015) Modulus of rupture evaluation of cement stabilized recycled glass/recycled concrete aggregate blends. Constr Build Mater 84:146-155

2. Chuah S, Pan Z, Sanjayan JG, Wang CM, Duan WH (2014) Nano reinforced cement and concrete composites and new perspective from graphene oxide. Constr Build Mater 73:113-124

3. Du H, Tan KH (2013) Use of waste glass as sand in mortar: Part II-Alkalisilica reaction and mitigation methods. Cement Concr Compos 35(1):118-126

4. Du H, Tan KH (2014) Effect of particle size on alkali-silica reaction in recycled glass mortars. Constr Build Mater 66:275-285

5. Du H, Tan KH (2015) Transport properties of concrete with glass powder as supplementary cementitious material. ACI Mater J 112(3):429

6. Du H, Tan KH (2017) Properties of high volume glass powder concrete. Cement Concr Compos 75:22-29

7. Duchesne J, Bérubé MA (1994) The effectiveness of supplementary cementing materials in suppressing expansion due to ASR: another look at the reaction mechanisms part 2: pore solution chemistry. Cem Concr Res 24(2):221-230

8. Hamilton HR, Boyd AJ, Vivas EA (2007) Permeability of concrete- 
comparison of conductive and diffusion methods. Final Report submitted to Florida Department of Transportation" (Contract No. BD536)

9. Hobbs DW (1980) The effect of pulverized-fuel ash upon the workability of cement paste and concrete. Mag Concr Res 32(113):219-226

10. Johnston CD (1974) Waste glass as coarse aggregate for concrete. J Test Eval 2(5):344-350

\section{AQ3}

11. Kamali M, Ghahremaninezhad A (2016) An investigation into the hydration and microstructure of cement pastes modified with glass powders. Constr Build Mater 112:915-924

12. Liu F, Meng LY, Ning GF, Li LJ (2015) Fatigue performance of rubbermodified recycled aggregate concrete (RRAC) for pavement. Constr Build Mater 95:207-217

13. López-Gayarre F, Viñuela RB, Serrano-López MA, López-Colina C (2015) Influence of the water variation on the mechanical properties of concrete manufactured with recycled mixed aggregates for pre-stressed components. Constr Build Mater 94:844-850

14. Lotfi S, Eggimann M, Wagner E, Mróz R, Deja J (2015) Performance of recycled aggregate concrete based on a new concrete recycling technology. Constr Build Mater 95:243-256

15. Mehta PK (2002) Greening of the concrete industry for sustainable development. Concr Int 24(7):23-28

16. Omran A, Tagnit-Hamou A (2016) Performance of glass-powder concrete in field applications. Constr Build Mater 109:84-95

17. Pereira-de-Oliveira LA, Castro-Gomes JP, Santos PM (2012) The potential pozzolanic activity of glass and red-clay ceramic waste as cement mortars components. Constr Build Mater 31:197-203

18. Rajabipour F, Maraghechi H, Fischer G (2010) Investigating the alkali-silica reaction of recycled glass aggregates in concrete materials. J Mater Civ Eng 22(12):1201-1208

19. Ramlochan T, Thomas M, Gruber KA (2000) The effect of metakaolin on 
alkali-silica reaction in concrete. Cem Concr Res 30(3):339-344

20. Saccani A, Bignozzi MC (2010) ASR expansion behavior of recycled glass fine aggregates in concrete. Cem Concr Res 40(4):531-536

21. Shang HS, Zhao TJ, Cao WQ (2015) Bond behavior between steel bar and recycled aggregate concrete after freeze-thaw cycles. Cold Reg Sci Technol $118: 38-44$

22. Shao Y, Lefort T, Moras S, Rodriguez D (2000) Studies on concrete containing ground waste glass. Cem Concr Res 30(1):91-100

23. Shayan A (2002) Value-added utilisation of waste glass in concrete. In: IABSE symposium report, vol 86, no 6, pp 12-21. International Association for Bridge and Structural Engineering

24. Shayan A, Xu A (2006) Performance of glass powder as a pozzolanic material in concrete: a field trial on concrete slabs. Cem Concr Res 36(3):457-468

25. Silva RV, Neves R, De Brito J, Dhir RK (2015) Carbonation behaviour of recycled aggregate concrete. Cem Concr Compos 62:22-32

26. Taha B, Nounu G (2008) Using lithium nitrate and pozzolanic glass powder in concrete as ASR suppressors. Cem Concr Compos 30(6):497-505

27. Topcu IB, Canbaz M (2004) Properties of concrete containing waste glass. Cem Concr Res 34(2):267-274 